\section{Cureus}

Received 02/17/2018

Review began 02/27/2018

Review ended 02/27/2018

Published 03/05/2018

\section{(c) Copyright 2018}

Ramphul et al. This is an open access article distributed under the terms of the Creative Commons Attribution License CC-BY 3.0., which permits unrestricted use, distribution, and reproduction in any medium, provided the original author and source are credited.

\title{
Morquio Syndrome: A Case Report
}

Kamleshun Ramphul $^{1}$, Stephanie G. Mejias ${ }^{2}$, Yogeshwaree Ramphul-Sicharam ${ }^{3}$

1. Pediatrics, Shanghai Jiao Tong University School of Medicine/Shanghai Xin Hua Hospital, Shanghai, CHN 2. Pediatrics, The University Iberoamericana Unibe School of Medicine/Robert Reid Cabral Children's Hospital, Santo Domingo, DOM 3. Sir Seewoosagur Ramgoolam National Hospital

$\square$ Corresponding author: Kamleshun Ramphul, adramphul@hotmail.com Disclosures can be found in Additional Information at the end of the article

\section{Abstract}

Mucopolysaccharidosis type IV (MPS IV), also known as Morquio syndrome, is a rare autosomal recessive lysosomal storage disease. The main features include skeletal defects and possible cardiopulmonary complications. The cost of diagnosing and treating this condition is high, and treatment is not easily available everywhere. We present a case of Morquio syndrome seen in a seven-year-old male from Iraq with multiple skeletal deformities.

Categories: Pediatrics

Keywords: morquio syndrome, mucopolysaccharidosis

\section{Introduction}

Mucopolysaccharidosis type IV (MPS IV), also known as Morquio syndrome, is a rare autosomal recessive lysosomal storage disease. The incidence of this disease ranges between 0.14 to 0.22 per 100,000 births [1]. Its main features include skeletal disorders such as short-trunk dwarfism, dental abnormalities, and possible cardiopulmonary complications. Morquio syndrome consists of MPS IV A, which results from mutations in galactosamine-6-sulfatase genes, and MPS IV B, which is due to beta-galactosidase deficiency [2-3]. We present a case of Morquio syndrome observed in Iraq.

\section{Case Presentation}

A seven-year-old male was brought to the clinic with an initial complaint of dwarfism and skeletal deformities. He was born from a non-consanguineous union. No family history of a similar condition was observed on either the maternal or paternal side. Upon examination, it was discerned that he had a pigeon-chest deformity, and a visible bowing of the lower extremities (Figures 1-2). The patient was then assessed and found to be with normal intelligence. Observations made were as follows: the height was in the 50th percentile with truncal dwarfism and the abdomen was distended, but no hepatosplenomegaly was observed in the patient. X-ray showed genu valgum in the lower extremities, with the bowing of lower legs as seen in Figure 3. 


\section{Cureus}

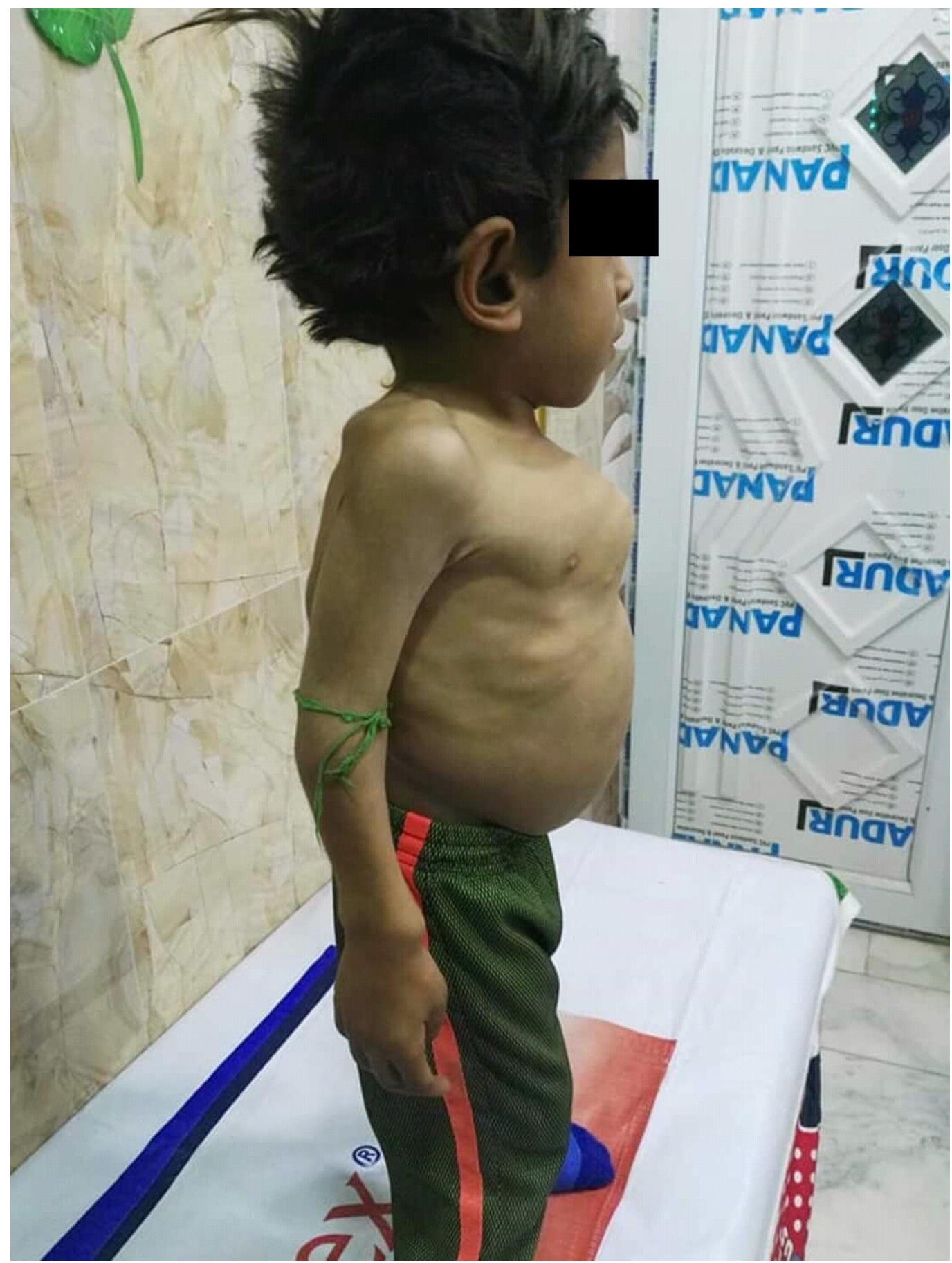

FIGURE 1: Male patient diagnosed with mucopolysaccharidosis type IV, having pigeon chest deformity and abdominal distension. 


\section{Cureus}

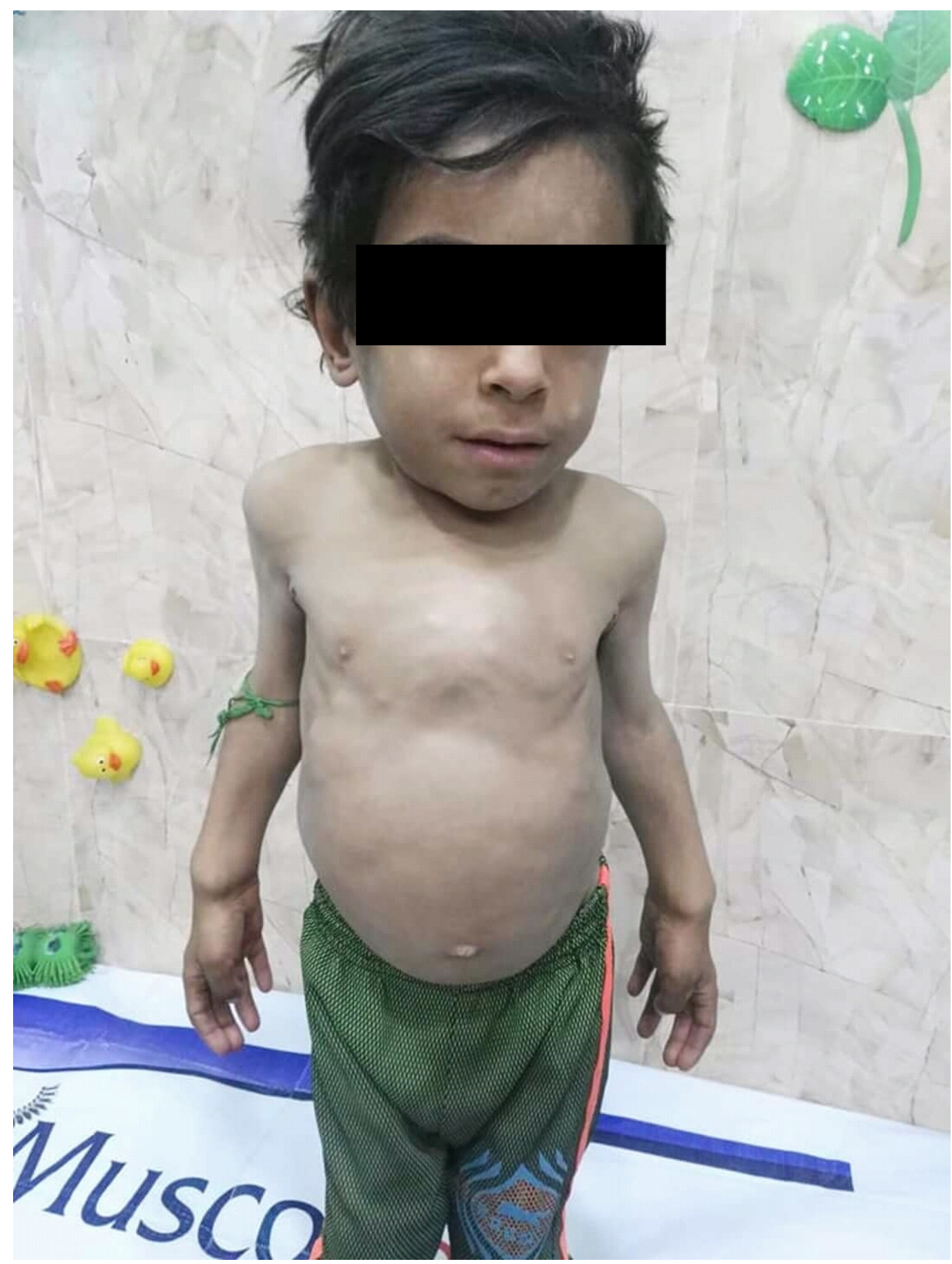

FIGURE 2: Abdominal distension in a male patient diagnosed with mucopolysaccharidosis type IV. 


\section{Cureus}

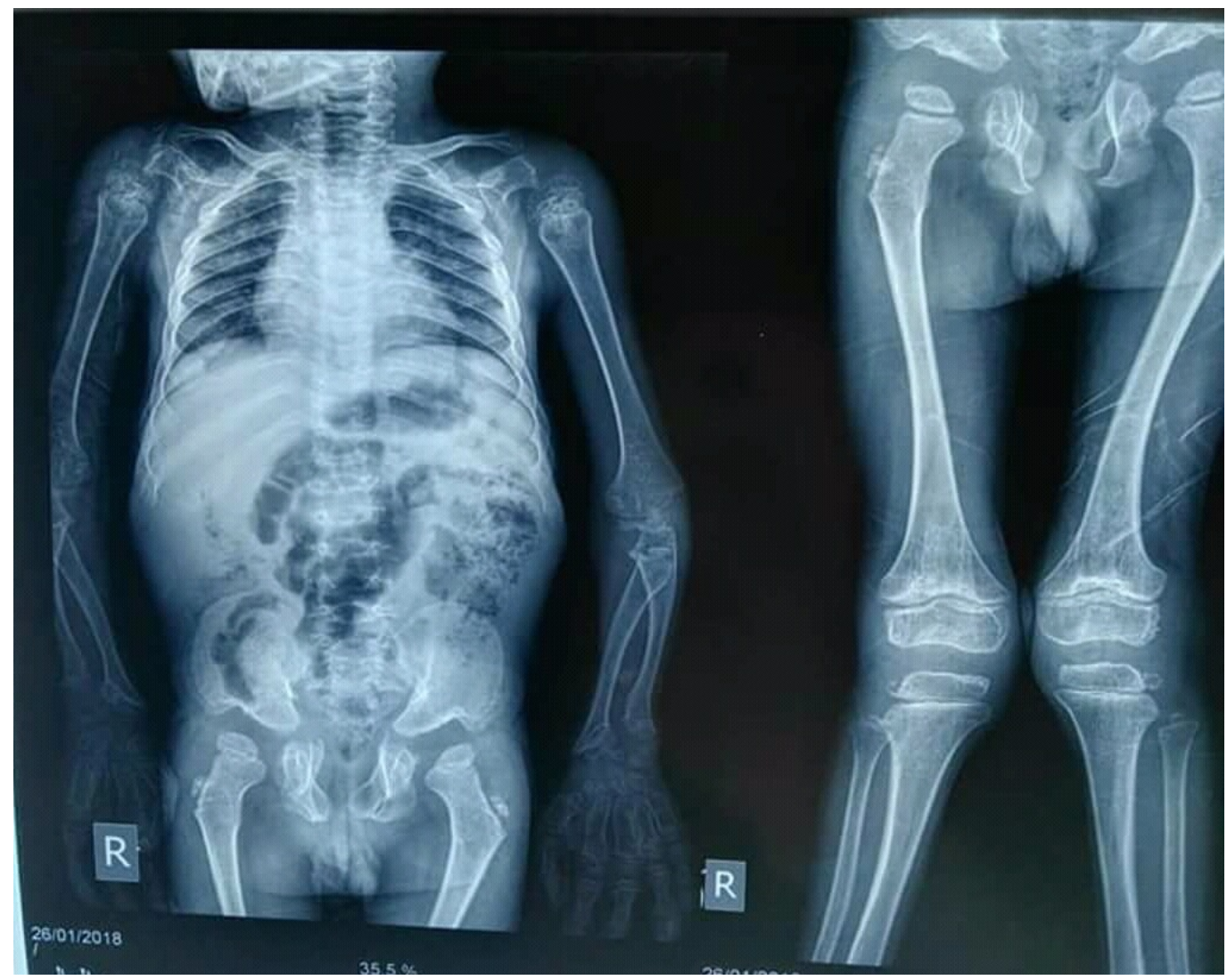

FIGURE 3: X-ray showed genu valgum in lower extremities with bowing of lower legs. No scoliosis was observed.

Further laboratory reports confirmed the presence of rickets and inclusion bodies in the lymphocytes of the patient. Due to a lack of proper infrastructure, enzyme and urine analysis were not available to confirm the enzyme defect. No cardiac or neurological abnormalities were noted on imaging. A slit-lamp examination did not reveal any corneal opacity. Following all the observations, a clinical diagnosis of Morquio syndrome was established. Initial differential diagnosis included Legg-Calve-Perthes disease, spondyloepiphyseal dysplasia, Hurler syndrome, and Hunter syndrome, among others.

The child was then referred to a geneticist, and the recommended treatment was Vimizim (BioMarin Pharmaceuticals Inc., Novato, California) (Elosulfase Alfa). Symptomatic care, and orthopedic follow-ups were also recommended for the musculoskeletal anomalies that may develop during his growth.

\section{Discussion}

Morquio syndrome is a rare condition, and is classified as type IV A and type IV B. An enzyme analysis will help to identify and confirm the diagnosis of Morquio syndrome in this patient. However, given the clinical presentation, the presence of inclusion bodies in the lymphocytes, and glycoaminoglycans (GAG) fragments in urine, a strong clinical diagnosis of Morquio syndrome can be made.

Treatment of Morquio syndrome includes enzyme replacement therapy of the deficient enzyme [4]. The cost of ERT is estimated to be around $\$ 380,000$ per year, making it a very expensive treatment option. Hematopoietic stem cell transplantation has also been established 
as a treatment option for patients with Morquio syndrome [5]. Toietta $\mathrm{G}$ et al. performed a gene therapy for Morquio syndrome in 2004, and there are multiple similar research studies

investigating cost-effective options [6].

The treatment plan for our patient that was recommended by the geneticist included possible enzyme replacement therapy. Elosulfase alfa, which goes by the tradename of Vimizim, is effective in young patients with Morquio syndrome. Some studies have found that it provides an improvement in respiratory symptoms, activities of daily living, and growth in Morquio syndrome patients [7]. Gene therapy and hematopoietic stem cell transplantation are, however, not possible given the geographic and financial settings of our patient.

\section{Conclusions}

There is a big financial dilemma surrounding Morquio syndrome. Proper diagnosis requires an enzyme study, which is not available in many underdeveloped countries. The treatment plan for our patient included enzyme replacement therapy, which might however be very costly and a major financial burden. With newer breakthroughs in science and medicine, hopefully one day there will be a cheaper and better alternative for patients suffering from Morquio syndrome.

\section{Additional Information \\ Disclosures}

Human subjects: Consent was obtained by all participants in this study. Conflicts of interest: In compliance with the ICMJE uniform disclosure form, all authors declare the following:

Payment/services info: All authors have declared that no financial support was received from any organization for the submitted work. Financial relationships: All authors have declared that they have no financial relationships at present or within the previous three years with any organizations that might have an interest in the submitted work. Other relationships: All authors have declared that there are no other relationships or activities that could appear to have influenced the submitted work.

\section{Acknowledgements}

We would like to thank Professor Razzaq Alrubaee from Nassiriyia, Iraq, for providing us with such a rare case and allowing us to share it. We are grateful for his help and support for making this case report possible.

\section{References}

1. Eggli KD, Dorst JP: The mucopolysaccharidoses and related conditions. Semin Roentogenol. 1988, 8:275-294. 10.1016/0037-198X(86)90039-8

2. Baker E, Guo X, Orsborn AM, et al.: The morquio A syndrome (mucopolysaccharidosis IVA) gene maps to 16q24.3. Am J Hum Genet. 1993, 52:96-98.

3. Singh J, DiFerrante NM, Niebes P, et al.: N-acetylgalactosamine-6-sulfate sulfatase in man. Absence of the enzyme in Morquio disease. J Clin Invest. 1976, 57:1036-1040. 10.1172/JCI108345

4. Yasuda E, Suzuki Y, Shimada T, et al.: Activity of daily living for Morquio A syndrome . Mol Genet Metab. 2016, 2:111-22. 10.1016/j.ymgme.2016.04.005

5. Boelens JJ: Trends in haematopoietic cell transplantation for inborn errors of metabolism . J Inherit Metab Dis. 2006, 2:413-20. 10.1007/s10545-005-0258-8

6. Toietta G, Severini GM, Traversari C, et al.: Various cells retrovirally transduced with Nacetylgalactosoamine-6-sulfate sulfatase correct Morquio skin fibroblasts in vitro. Hum Gene Ther. 2004, 12:2007-2016. 10.1089/104303401753204571

7. Hendriksz CJ, Giugliani R, Harmatz P et al.: Multi-domain impact of elosulfase alfa in Morquio A syndrome in the pivotal phase III trial. Mol Genet Metab. 2015, 114:178-185. 


\section{Cureus}

10.1016/j.ymgme.2014.08.012 